\title{
Gestão de um programa de pós-graduação em administração universitária a partir do sistema de avaliação da CAPES
}

\author{
Evandro Silveira Mestre em Administração. Universidade Federal de Santa Catarina - UFSC, Brasil. evandrosilve@gmail.com \\ Andressa Sasaki Vasques Pacheco Doutora em Engenharia e Gestão do Conhecimento. Universidade Federal de Santa Catarina - UFSC, Brasil. \\ andressa.ufsc@gmail.com
}

Jéssica Rocha de Souza Pereira Mestranda em Administração. Universidade Federal de Santa Catarina - UFSC, Brasil. jessicarspereira@gmail.com

\begin{abstract}
RESUMO
Esta pesquisa foi desenvolvida com o objetivo de propor mudanças à Gestão de um Programa de Pós-Graduação em Administração Universitária - Programa Alfa, que oferta o Mestrado Profissional em Administração Universitária, frente ao Sistema de Avaliação da Coordenação de Aperfeiçoamento de Pessoal de Nível Superior - CAPES. O estudo é produto de uma pesquisa de natureza aplicada, descritiva, de abordagem predominantemente qualitativa. Como resultado constatou-se que a proposta do programa necessita de ajustes, pois foram identificadas insuficiências para um Mestrado Profissional, como a ênfase em questões teóricas e má distribuição do corpo docente nas linhas de pesquisa. Observouse que o programa conta com um corpo docente com perfil acadêmico e profissional adequado, com pequena oscilação de membros. Foi possível identificar inconsistências na vinculação das dissertações às linhas de pesquisa informadas. Por fim, recomendou-se um planejamento das atividades do Programa Alfa, objetivando alinhamento e consonância com os critérios de avaliação da CAPES. O cenário atual apresenta a tendência de o Programa Alfa permanecer com a nota 3. A partir de ajustes sugeridos para a Proposta e Inserção Social, abre-se a possibilidade para uma nota 4.
\end{abstract}

Palavras-chave: Avaliação. Pós-Graduação. CAPES. Mestrado Profissional.

\section{Management of the graduate administration university program from the CAPES evaluation system}

\begin{abstract}
This research was developed in order to propose changes to the management of the Graduate Program in University Administration - Programa Alfa, which offers the Professional Master in University Administration, under the Assessment System of Higher Education Personnel Improvement Coordination - CAPES. The study is linked to the line of research Academic and Administrative Management and it is the result of applied research, descriptive, and mainly qualitative approach. It consists of a case study and adopts documentary research. As a result, it was found that the Proposed Program needs adjustments as shortcomings for a Professional Master such as emphasis on theoretical issues and poor distribution of faculty in research lines were identified. It was observed that the program has a team of professors with appropriate academic and professional profiles and there is little oscillation among members. The program presented a good proportion of graduates. It was possible to identify inconsistencies in linking the dissertations to the informed research lines. Finally, a plan for the activities of Programa Alfa was recommended, aiming at an alignment and in consonance with the evaluation criteria of CAPES. The current scenario shows the tendency for Programa Alfa to remain with the evaluation grade 3. After the adjustments suggested for the Proposal and Social Inclusion, there is the possibility of achieving a grade 4 .
\end{abstract}

Keywords: Evaluation. Post graduate studies. CAPES. Professional Master. 


\section{INTRODUÇÃO}

As universidades são desafiadas a intervir na realidade da comunidade na qual estão inseridas e contribuir no processo de formação de profissionais com qualidade, de distintas áreas, a fim de habilitá-los ao mercado de trabalho (ASSIS; BONIFÁCIO, 2011). Para Chauí (2003), as universidades públicas sempre foram reconhecidas como instituições de caráter social, fundamentadas no reconhecimento de sua legitimidade e atribuições, apresentando uma série de distinções que são responsáveis por conferir autonomia em relação a outras instituições.

Um aspecto significativo para a gestão de qualquer instituição é a Avaliação; para uma instituição universitária isto não é diferente. A universidade está constantemente sendo avaliada e, para Oliveira, Fonseca e Amaral (2006, p. 78) "a avaliação busca a melhoria da instituição e dos processos de gestão no seu interior".

O processo de avaliação de uma instituição de ensino superior está concentrado nos processos e produtos da academia, entretanto, por si só, este foco não é capaz de modificar o ensino. Dessa forma, é relevante envolver no processo de avaliação aspectos inerentes à própria cultura institucional (OLIVEIRA; FONSECA; AMARAL, 2006). Ao se discutir a temática Pós-Graduação stricto sensu, torna-se oportuno considerar o papel desempenhado pela Coordenação de Aperfeiçoamento de Pessoal de Nível Superior - CAPES. Vinculada ao Ministério da Educação - MEC, atua na expansão e consolidação da pós-graduação stricto sensu em todo o Brasil (CAPES, 2012).

Dentre suas atribuições, a CAPES é responsável pela avaliação da pós-graduação stricto sensu (CAPES, 2012). E, é essa atribuição que o presente estudo aborda, especificamente em relação à avaliação dos mestrados profissionais, a fim de se observar quais aspectos são importantes para a gestão da pós-graduação. Segundo Maccari et al (2014), é a CAPES quem desenvolve e aprimora o Sistema de Avaliação da Pós-Graduação desde 1976. Para os autores, a informatização e a adoção de critérios mais rígidos para atribuição de notas aos programas, a partir de 1990, foi um grande progresso no sistema de avaliação.

Essa avaliação pondera, de forma distinta, os pesos dos aspectos a serem avaliados para os mestrados e doutorados de nível acadêmico e mestrados profissionais. O Mestrado Profissional é regulamentado pela Portaria Normativa no 17, de 28 de dezembro de 2009, e consiste em um curso de pós-graduação stricto sensu orientado para profissionais das diversas áreas do conhecimento, e prevê o estudo de técnicas e processos que atendam a alguma demanda social, organizacional ou de mercado de trabalho (BRASIL, 2009).

Um dos cursos hoje credenciados é o Mestrado Profissional em Administração Universitária - Programa Alfa, ofertado desde 2010, objeto do estudo que ora é apresentado neste artigo, o qual tem como área de concentração a Gestão Universitária.

Na última avaliação realizada pela CAPES o Programa Alfa obteve conceito 3, devendo-se considerar relevante todo e qualquer esforço que tenha como escopo melhorar suas condições de oferta e, por conseguinte, do seu conceito. Neste contexto, surge a seguinte pergunta de pesquisa: como contribuir com o aperfeiçoamento da gestão do

\section{Programa Alfa a partir do Sistema de Avaliação da CAPES?}

Para responder ao problema de pesquisa exposto, este trabalho tem como objetivo geral propor mudanças à

\section{Gestão do Programa Alfa a partir do Sistema de Avaliação da CAPES.}

Para alcançar o objetivo geral proposto, foram elencados os seguintes objetivos específicos:

a) Analisar a proposta atual do Programa Alfa;

b) Avaliar o corpo docente do Programa Alfa;

c) Avaliar o corpo discente e as dissertações do Programa Alfa.

\section{GESTÃO UNIVERSITÁRIA}

Nas universidades brasileiras, as questões relacionadas à gestão universitária normalmente são associadas a atributos de natureza técnica, e fundamentadas em princípios isolados da eficiência e eficácia, aspectos particulares do modelo produtivista de mercado (SAMPAIO; LANIADO, 2009).

Já, Silva Filho (1998), compreende as especificidades da universidade e afirma que a Gestão Universitária reside na mescla da visão acadêmica e da técnica administrativa. $O$ autor segue considerando que a referida mescla deve permitir o "controle institucional, a busca de objetivos comuns e globais sem inibir ou amordaçar a capacidade individual de gerar ideias, conhecimentos e tecnologias" (SILVA FILHO, 1998, p. 1).

Torna-se importante, então, compreender o que é a administração universitária. Neste trabalho, adota-se a definição de Schlickmann (2013, p. 47), que caracteriza a administração universitária como um "processo de planejar, organizar, liderar e controlar o trabalho dos membros da universidade, e de usar todos os seus recursos disponíveis para atingir os objetivos de: formar quadros profissionais de nível superior; realizar pesquisa e extensão". 
Este conceito acolhe bem o atual ambiente de crescimento de demanda pelo ensino superior, quando se percebe a necessidade de profissionalização na área de Gestão Universitária. Tanto os números como os recursos financeiros das universidades aumentaram, sendo assim, seus gestores não podem ser ineficientes e o serviço ofertado não pode ser baseado na tentativa e erro (SILVA FILHO, 1998).

Em meio à caracterização da gestão universitária, surge a questão do planejamento institucional, que Bertoldi, Colossi e Ronchi (2004, p. 171) definem como "um instrumento efetivo da gestão e, seu propósito é criar a visão de futuro da instituição através da concepção e elaboração do seu Plano de Desenvolvimento Institucional". O Plano de Desenvolvimento Institucional constituiu-se, segundo os mesmos autores, em um documento que permite apontar dificuldades e deficiências de uma instituição, além de definir oportunidades relacionadas ao ambiente.

Para Bertoldi, Colossi e Ronchi (2004, p. 172), o Plano de Desenvolvimento Institucional possibilita "liberar, um potencial criativo e inovador próprio no ambiente educacional. Na realidade, o PDI ajuda a gestão a pensar o futuro da instituição: investir em formação e qualificação docente e do pessoal técnico administrativo".

Além do Plano de Desenvolvimento Institucional, outro aspecto que emerge da Gestão Universitária é a avaliação institucional. Desta forma, a próxima seção se destina a abordar a temática.

\subsection{Avaliação Institucional}

A avaliação institucional, segundo Zanetti, Bertolini e Silva (1995), é responsável pelo nível de qualidade do trabalho acadêmico, portanto, não deve atender interesses destoantes ou particulares. Abreu Junior (2009) converge com Zanetti, Bertolini e Silva (1995) ao afirmar que seu objetivo básico é elevar o nível de qualidade de uma instituição educacional. Dessa forma, coloca-se em evidência a sua importância, assim como a atenção merecida por parte da Universidade.

Neste sentido, Santos, Sadala e Borges (2012, p. 552), reconhecem a avaliação institucional como "instrumento eficiente na correção de deficiências, agindo, enquanto processo, para desenvolver a excelência da qualidade do ensino". Abreu Junior (2009, p. 267) recomenda que não seja empregado um sistema de avaliação a partir de "medidas ou procedimentos universais, incontestáveis ou absolutos", a fim de que sejam respeitadas as especificidades que cada instituição possui.

Em se tratando de avaliação, surge a necessidade de apresentar o Sistema Nacional de Avaliação da Educação Superior - SINAES. Criado pela Lei $n^{\circ} 10.861$, de 14 de abril de 2004, está concentrado em avaliar as instituições, os cursos e o desempenho dos estudantes (BRASIL, 2004). Atualmente, é o Instituto Nacional de Estudos e Pesquisas Educacionais Anísio Teixeira - INEP o responsável por operacionalizar o SINAES (INEP, 2015). Além do SINAES, a pós-graduação está submetida a outro sistema de avaliação, a avaliação realizada pela CAPES. Dessa forma, nas próximas seções, pretendese abordar a questão da avaliação da pós-graduação.

\subsection{Avaliação da pós-graduação no Brasil}

Por meio do Decreto № 29.741, de 11 de julho de 1951, foi instituída a Coordenação de Aperfeiçoamento de Pessoal de Nível Superior - CAPES, na época, sob a Presidência do Ministro da Educação e Saúde, com os seguintes objetivos (BRASIL, 1951):

a) assegurar a existência de pessoal especializado em quantidade e qualidade suficientes para atender às necessidades dos empreendimentos públicos e privados que visam o desenvolvimento econômico e social do país.

b) oferecer aos indivíduos mais capazes, sem recursos próprios, acesso a todas as oportunidades de aperfeiçoamentos.

Atualmente, a CAPES é vinculada ao Ministério da Educação e opera na expansão e consolidação da pósgraduação stricto sensu em todo o Brasil. A partir de 2007 passou a atuar na formação de professores da educação básica com o objetivo de ampliar a formação de pessoal qualificado (CAPES, 2012).

A CAPES é responsável pelas seguintes atividades (CAPES, 2012):

a) avaliação da pós-graduação stricto sensu;

b) acesso e divulgação da produção científica;

c) investimentos na formação de recursos de alto nível no país e exterior;

d) promoção da cooperação científica internacional; e

e) indução e fomento da formação inicial e continuada de professores para a educação básica nos formatos presencial e a distância 
A avaliação aplicada pela CAPES (2014) objetiva:

a) Certificação da qualidade da pós-graduação Brasileira;

b) Identificação de assimetrias regionais e de áreas estratégicas do conhecimento no SNPG para orientar ações de indução na criação e expansão de programas de pós-graduação.

É possível dividir a avaliação em dois processos, um referente à entrada e outro à permanência dos cursos de pós-graduação stricto sensu. Ambos os processos são executados com base nos seguintes fundamentos: reconhecimento e confiabilidade; critérios debatidos e atualizados; e transparência (CAPES, 2014).

Os mestrados profissionais são a modalidade mais recente de pós-graduação stricto sensu brasileira e, por conta disto, "apresentam novas dificuldades quanto à sua avaliação" (NEPOMUCENO; COSTA, 2012, p. 1). Neste sentido, sua avaliação apresenta algumas diferenças e, para a execução deste processo, são gerados os chamados documentos de área. Esses documentos servem como orientação para os próximos períodos avaliativos, assim como para a proposição de cursos novos. $\mathrm{O}$ documento de área descreve o estado atual dos programas, as características e as perspectivas. $\mathrm{O}$ documento contempla também quesitos considerados prioritários na avaliação dos programas (CAPES, 2014).

Em complemento ao documento de área, existem as Fichas de Avaliação e os Relatórios de Avaliação, todos resultantes da Avaliação Trienal, aplicada até 2012. O relatório apresenta o resultado geral do período avaliativo, além de descrever os critérios e métricas utilizadas para avaliação de cada aspecto. O relatório é construído a partir dos dados informados pelo próprio programa, analisado pelas fichas de avaliação (CAPES, 2014). As fichas de avaliação são o resultado da análise da Proposta do programa, do corpo docente, do corpo discente e trabalhos de conclusão, da Produção intelectual, e da Inserção social do programa. A ficha apresenta, ainda, o conceito atribuído ao programa que, pode variar entre: deficiente, fraco, regular, bom e muito bom.

Para analisar os itens de avaliação, a CAPES faz uso de métricas referentes à proposta, ao corpo docente, ao corpo discente e trabalhos de conclusão, produção intelectual e inserção social; as métricas são utilizadas com o intuito de atribuir de uma melhor forma o conceito a cada item de avaliação. Neste trabalho, utilizaram-se as métricas referentes à proposta, ao corpo docente, ao corpo discente e trabalho de conclusão, conforme o Quadro 1.

Quadro 1 - Métricas de avaliação para mestrado profissional

\begin{tabular}{|c|c|}
\hline ASPECTO & MÉTRICA \\
\hline Proposta & - Avaliação qualitativa. \\
\hline \multirow{8}{*}{ Corpo docente } & $\begin{array}{l}\text { - Proporção do Núcleo Docente Permanece - NDP com perfil } \\
\text { profissional qualificado. }\end{array}$ \\
\hline & - Proporção do NDP com perfil acadêmico qualificado. \\
\hline & - Proporção do NDP (\%). \\
\hline & - Vínculo dos docentes permanentes em programas \\
\hline & - Oscilação do corpo docente permanente. \\
\hline & $\begin{array}{l}\text { - Proporção dos docentes permanentes com no mínimo } 30 \\
\text { horas-aula anuais no programa. }\end{array}$ \\
\hline & $\begin{array}{l}\text { - Proporção dos docentes permanentes com liderança em } \\
\text { projetos de pesquisa, desenvolvimento e inovação em } \\
\text { organizações públicas ou privadas. }\end{array}$ \\
\hline & $\begin{array}{l}\text { - Proporção dos docentes permanentes que concluíram, no } \\
\text { mínimo, duas orientações de discentes do PPG no triênio, } \\
\text { excluídos as exceções. }\end{array}$ \\
\hline \multirow{6}{*}{$\begin{array}{l}\text { Corpo discente } \\
\text { e trabalhos de } \\
\text { conclusão }\end{array}$} & $\begin{array}{l}\text { - Proporção de titulados no ano-base considerando-se o } \\
\text { número de discentes no final do ano-anterior. }\end{array}$ \\
\hline & $\begin{array}{l}\text { - Proporção de docentes permanentes com mais de } 8 \text { e menos } \\
\text { ou igual a } 12 \text { orientandos ao final de cada ano. }\end{array}$ \\
\hline & $\begin{array}{l}\text { - Proporção das bancas de trabalho de conclusão com } \\
\text { examinadores externos ao Programa. }\end{array}$ \\
\hline & $\begin{array}{l}\text { - Proporção de trabalhos de conclusão vinculados às linhas de } \\
\text { atuação. }\end{array}$ \\
\hline & $\begin{array}{l}\text { - Proporção de discentes e egressos autores na produção } \\
\text { científica, técnica e tecnológica. }\end{array}$ \\
\hline & - Avaliação qualitativa. \\
\hline
\end{tabular}

Fonte: Adaptado de CAPES (2013)

Para que a CAPES possa analisar todos estes aspectos, os programas de pós-graduação são responsáveis pela informação de todos os dados necessários. Assim que um curso de pós-graduação stricto sensu é recomendado pela CAPES e reconhecido pelo Conselho Nacional de Educação ele fica obrigado a prestação de informações à CAPES, responsável por sua avaliação (CAPES, 2015).

Os programas são solicitados a prestarem informações sobre a sua infraestrutura física, formação e atividades de docentes, matrícula e titulação de alunos, disciplinas oferecidas, produção bibliográfica, dissertações e teses 
defendidas, produção técnica e tecnológica, entre outros (CAPES, 2015). Com a criação da Plataforma Sucupira, o sistema de coleta de dados foi reformulado para ser incorporado à plataforma (CAPES, 2015).

Muitas das informações solicitadas pela CAPES são passíveis de importação pela plataforma Lattes como, por exemplo, os dados constantes dos currículos Lattes dos docentes referentes às produções bibliográficas, técnicas e Artísticas/Culturais vinculadas ao programa. A Plataforma Lattes é a integração de bases de dados de Currículos, Grupos de pesquisa e Instituições (CNPq, 2015).

\section{PROCEDIMENTOS METODOLÓGICOS}

Este estudo é de natureza aplicada, descritiva, de abordagem predominantemente qualitativa. Além disso, consiste em um estudo de caso e adota a pesquisa bibliográfica e documental.

Quanto à sua natureza, é classificada como pesquisa aplicada que, para Silva e Menezes (2005, p. 20), visa "gerar conhecimentos para aplicação prática dirigidos à solução de problemas específicos". A partir disso, chegou-se a um material capaz de contribuir com o aperfeiçoamento da gestão do Programa Alfa.

Já, a classificação dos objetivos é descritiva, que Gil (2002) considera como aquela que objetiva a descrição das características de uma população, fenômeno ou de uma experiência. Neste estudo, visou-se a descrição de aspectos relacionados ao aperfeiçoamento da gestão do Programa Alfa a partir do Sistema de Avaliação da CAPES.

Embora sejam empregados recursos quantitativos para analisar o programa, nesta pesquisa, a abordagem foi predominantemente qualitativa que, para Souza, Fialho e Otani (2007, p. 39) "considera que há uma relação dinâmica entre o mundo real e o sujeito, isto é, um vínculo indissociável entre o mundo objetivo e a subjetividade do sujeito que não pode ser traduzido em números". Neste trabalho, buscou-se um aprofundamento do caso estudado.

Este trabalho é classificado ainda como estudo de caso, que Gil (1999, p. 72) define como aquele "caracterizado pelo estudo profundo e exaustivo de um ou de poucos objetos, de maneira a permitir o seu conhecimento amplo e detalhado". O caso analisado foi o do Programa Alfa, enquanto que as unidades de análise foram a proposta, o corpo docente e o corpo discente do próprio programa.

Em relação aos métodos, o estudo foi realizado por meio de materiais já publicados, como principalmente de livros, artigos e material disponibilizado na Internet no que se refere a temas como Universidade, Gestão Universitária, Avaliação Institucional, Avaliação da Pós-Graduação e Sistema de Avaliação da CAPES. Caracterizando-se assim, como bibliográfica que, para Souza, Fialho e Otani (2007), é aquela oriunda da obtenção de dados por meio de fontes secundárias. Além dos livros físicos, foram realizadas buscas nas bases de dados Scielo e Portal de Periódicos da CAPES.

A coleta de dados foi predominantemente documental. Para Yin (2015, p. 109-110), a informação documental é muito relevante para os estudos de caso de forma geral, pois "esse tipo de informação pode tomar várias formas e deve ser objeto de planos explícitos de coleta de dados".

Dessa forma, foram analisados os relatórios originados do Sistema de Gestão Acadêmica da Pós-Graduação da Universidade pesquisada, os currículos lattes de docentes e discentes, as resoluções e o próprio regimento do Programa Alfa. Além disso, foram analisados os seguintes documentos gerados pela CAPES: relatórios de Avaliação do Programa Alfa e relatórios de Avaliação por áreas.

Quanto à proposta do programa, foi instituída uma comissão que fez uma análise documental. A análise foi realizada a partir dos critérios considerados pela CAPES no momento de avaliação, o que possibilitou a indicação de melhorias.

Também em relação ao corpo docente do programa foi feita uma análise documental, a partir das informações obtidas junto à Plataforma Sucupira, à Plataforma Lattes e aos relatórios do sistema da Universidade analisada.

Por uma questão de sigilo e ética, o programa, objeto de estudo desta pesquisa, não foi identificado, sendo utilizada uma codificação para sua apresentação: Programa Alfa.

\section{APRESENTAÇÃO E ANÁLISE DOS RESULTADOS}

A seguir apresenta-se a análise do programa referente a sua proposta, ao corpo docente, ao corpo discente e trabalhos de conclusão. 


\subsection{Proposta}

Para a análise deste quesito é importante ressaltar que, por uma portaria de 2015 do Programa Alfa, foi constituída uma Comissão para reestruturação da Proposta do Programa. A comissão partiu da avaliação da Ficha de avaliação do programa referente ao último período avaliativo (2010-2012), e buscou diagnosticar a necessidade de ajustes na configuração da Proposta em relação às Linhas de Pesquisa e Disciplinas do Programa. Os elementos foram avaliados por quatro quesitos: coerência; consistência; abrangência; e atualização das áreas de concentração, linhas de atuação etc.

O único quesito avaliado de forma positiva foi a Infraestrutura para ensino, pesquisa e administração, considerado Muito Bom. Dessa forma, a Comissão buscou nos documentos de avaliação quais problemas o Programa apresentava em sua proposta.

Quanto às linhas do Programa, o problema principal identificado foi o desequilíbrio das produções e projetos entre as duas linhas existentes, causado, sobretudo, pela atuação da maioria dos docentes em apenas uma delas. Outra questão identificada foi que as descrições das linhas de pesquisa ou não estavam suficientemente claras ou estavam sem o direcionamento requerido por uma "linha" de pesquisa. Dessa forma, a Comissão sugeriu a criação de novas linhas de pesquisa que melhor refletissem as competências dos docentes do programa, possibilitando a distribuição destes docentes de forma mais coerente.

Quanto às disciplinas, com base da ficha de avaliação, buscou-se consonância com as novas linhas de pesquisa e reforçar o eixo profissional do programa. Assim, a comissão propôs criação de pelo menos uma disciplina com caráter prático ou teórico-prático alinhada a cada linha de pesquisa, ministrada por pelo menos três professores, com atuação preponderante daquela linha.

\subsection{Corpo Docente}

O corpo docente do Programa Alfa, entre os anos de 2014 e 2015 se manteve com o mesmo número, contabilizando 19 docentes permanentes entre os anos 2013 e 2015 . O corpo docente é avaliado pela CAPES por três itens de avaliação. O primeiro item visa avaliar o perfil do corpo docente e considera a experiência do docente como pesquisador e/ou profissional, titulação e sua adequação à proposta do Programa. A explicação sobre as métricas de avaliação está disposta no quadro 1.

Este primeiro item é analisado a partir de três métricas - apresentadas na Figura 1. As métricas utilizam os conceitos atribuídos ao programa que, pode variar entre: deficiente - D, fraco - F, regular - $R$, bom - B e muito bom - MB.

Figura 1 - Avaliação do perfil do corpo docente

\begin{tabular}{|c|c|c|}
\hline $\begin{array}{l}\text { Métrica } 1 \text { Proporção } \\
\text { do NDP }(\%) \text { com perfil } \\
\text { profissional qualificado }\end{array}$ & $\begin{array}{l}\text { Métrica } 2 \text { Proporção } \\
\text { do NDP com perfil } \\
\text { acadêmico qualificado }\end{array}$ & $\begin{array}{l}\text { Métrica } 3 \text { Proporção } \\
\text { do NDP }(\%)\end{array}$ \\
\hline $\mathrm{MB}>\mathrm{ou}=\mathrm{a} 40$ & $\mathrm{MB}>\mathrm{ou}=\mathrm{a} 40$ & $\mathrm{MB}<$ que 40 \\
\hline $\begin{array}{l}\mathrm{B}>\text { ou }=\text { a } 35 \\
\text { mas }<\text { que } 40\end{array}$ & $\begin{array}{l}\mathrm{B}>\text { ou }=\text { a } 35, \\
\text { mas }<\text { que } 40\end{array}$ & $\begin{array}{l}\mathrm{B}>\text { ou }=\mathrm{a} 40, \\
\text { mas }<\text { que } 50\end{array}$ \\
\hline $\begin{array}{l}\mathrm{R}>\text { ou }=\text { a } 30 \\
\text { mas }<\text { que } 35\end{array}$ & $\begin{array}{l}\mathrm{R}>\text { ou }=\text { a } 30 \\
\text { mas }<\text { que } 35\end{array}$ & $\begin{array}{l}\mathrm{R}>\text { ou }=\text { a } 50 \\
\text { mas }<\text { que } 60\end{array}$ \\
\hline $\begin{array}{l}\mathrm{F}>\text { ou }=\text { a } 25 \\
\text { mas }<\text { que } 30\end{array}$ & $\begin{array}{l}\mathrm{F}>\mathrm{ou}=\mathrm{a} 25, \\
\text { mas }<\text { que } 30\end{array}$ & $\begin{array}{l}\mathrm{F}>\text { ou }=\text { a } 60 \\
\text { mas }<\text { que } 70\end{array}$ \\
\hline $\mathrm{D}<$ que 25 & D $<$ que 25 & $\mathrm{D}>\mathrm{ou}=\mathrm{a} 70$ \\
\hline
\end{tabular}

Fonte: Elaborado pelos autores a partir da Capes (2013).

Ao se analisar os currículos dos 19 docentes permanentes que compuseram o corpo docente do Programa Alfa entre 2013 e 2015, constatou-se que todos apresentam ao menos dois aspectos considerados para a Métrica 1. Dessa forma, pode-se concluir que o corpo docente do Programa apresenta um perfil profissional adequado, conceituado como Muito Bom. 
Já a Métrica 2, com o intuído de analisar o perfil acadêmico do corpo docente, foi concebida a partir da "experiência na liderança de projetos com financiamentos externos em processos competitivos, a experiência didática em cursos stricto sensu, a realização de pós-doutoramento, orientações, entre outros indicadores de experiência acadêmica" (CAPES, 2013, p. 32). Verificou-se que todos os docentes já atuaram na docência em pós-graduação Stricto Sensu. Outra informação levantada foi de que apenas 5 dos 19 possuem pós-doutorado.

A métrica 3 não foi apresentada com clareza no Relatório de avaliação 2007-2009 trienal 2010, não ficou evidente o que havia sido mensurado. Dessa forma, foi realizado contato com a Coordenação de Área de Administração, Ciências Contábeis e Turismo. A partir do contato, foi afirmado que a métrica serviu para avaliar a diversidade de formação do corpo docente. Porém, não houve detalhamento dos critérios adotados para enquadrar nos conceitos Muito Bom, Bom, Regular Fraco e Deficiente.

O segundo item de avaliação do corpo docente tem por finalidade analisar a adequação da dimensão, composição e dedicação dos docentes permanentes para o desenvolvimento das atividades de pesquisa e formação do Programa. Este item utiliza duas métricas para a avaliação, conforme apresentado na Figura 2.

Figura 2 - Adequação dos docentes permanentes

\begin{tabular}{|c|c|}
\hline $\begin{array}{l}\text { Métrica } 1 \text { - Vínculo dos docentes } \\
\text { permanentes em programas } \\
\text { rofissional + Profissional/ } \\
\text { Profissional + Acadêmico } \\
\text { roporção do NDP }(\%) \\
\text { MB }<\text { ou }=\text { a } 70 \\
3>70, \text { mas }<\text { que } 75 \\
>75, \text { mas }<\text { que } 80 \\
>80, \text { mas }<\text { que } 85 \\
>\text { que } 85\end{array}$ & $\begin{array}{l}\text { Métrica } 2 \text { - Oscilação do corpo docente } \\
\text { permanente. Média da proporção de } \\
\text { docentes permanentes mantida no NDP a } \\
\text { cada ano do triênio, tomando como base } \\
\text { o ano anterior. Conceito Proporção do } \\
\text { NDP }(\%) \\
\text { MB }>\text { ou }=\text { a } 75 \\
\text { B }>\text { ou }=\text { a } 65, \text { mas }<\text { que } 75 \\
\text { R }>\text { ou }=\text { a } 55, \text { mas }<\text { que } 65 \\
\text { F }>\text { ou }=\text { a } 45, \text { mas }<\text { que } 55 \\
\text { D }<\text { que } 45\end{array}$ \\
\hline
\end{tabular}

Fonte: Elaborado pelos autores a partir da Capes (2013).

A partir das métricas, foram calculados os valores para os anos 2013, 2014 e 2015. Com o cálculo da métrica 1, foi possível observar que o Programa Alfa não apresenta problemas quanto ao número de docentes que fazem parte de outro programa de pós-graduação. Em 2013, o programa foi avaliado como "BOM" e nos anos seguintes, 2014 e 2015, atingiu o conceito "MUITO BOM". O cálculo da Métrica 2 também foi positivo para o triênio 2013 a 2015.

O terceiro item de avaliação do corpo docente tem por finalidade verificar a distribuição das atividades de pesquisa, projetos de desenvolvimento e inovação e de formação entre os docentes do Programa. Para tanto, adota 3 métricas. A Figura 3 a seguir, apresenta essas métricas e os parâmetros utilizados para cada resultado.

Figura 3 - Distribuição das atividades desempenhadas pelos docentes

\begin{tabular}{|c|c|c|}
\hline $\begin{array}{l}\text { Métrica } 1 \text { - Proporção } \\
\text { dos docentes } \\
\text { permanentes com no } \\
\text { mínimo } 30 \text { horas-aula } \\
\text { anuais no programa. } \\
\text { Conceito Proporção do } \\
\text { NDP }(\%)\end{array}$ & $\begin{array}{l}\text { Métrica } 2 \text { - Proporção dos } \\
\text { docentes permanentes } \\
\text { com liderança em } \\
\text { projetos de pesquisa, } \\
\text { desenvolvimento e } \\
\text { inovação em } \\
\text { organizações públicas ou } \\
\text { privadas. } \\
\text { Conceito Proporção do } \\
\text { NDP }(\%)\end{array}$ & $\begin{array}{l}\text { Métrica } 3 \text { - Proporção dos } \\
\text { docentes permanentes } \\
\text { que concluíram, no } \\
\text { mínimo, duas orientações } \\
\text { de discentes do PPG no } \\
\text { triênio, excluídos as } \\
\text { exceções. } \\
\text { Conceito Proporção do } \\
\text { NDP (\%) }\end{array}$ \\
\hline $\mathrm{MB}>\mathrm{ou}=\mathrm{a} 90$ & $\mathrm{MB}>\mathrm{ou}=\mathrm{a} 60$ & $\mathrm{MB}>\mathrm{ou}=\mathrm{a} 90$ \\
\hline $\begin{array}{l}\mathrm{B}>\mathrm{ou}=\text { a } 80, \\
\text { mas }<\text { que } 90\end{array}$ & $\begin{array}{l}\mathrm{B}>\mathrm{ou}=\text { a } 55, \\
\text { mas }<\text { que } 60\end{array}$ & $\begin{array}{l}\mathrm{B}>\mathrm{ou}=\text { a } 80 \\
\text { mas }<\text { que } 90\end{array}$ \\
\hline $\begin{array}{l}\mathrm{R}>\mathrm{ou}=\mathrm{a} 70 \\
\text { mas }<\text { que } 80\end{array}$ & $\begin{array}{l}\mathrm{R}>\mathrm{ou}=\text { a } 50, \\
\text { mas }<\text { que } 55\end{array}$ & $\begin{array}{l}\mathrm{R}>\mathrm{ou}=\mathrm{a} 70 \\
\text { mas }<\text { que } 80\end{array}$ \\
\hline $\begin{array}{l}\mathrm{F}>\mathrm{ou}=\text { a } 60 \\
\text { mas }<\text { que } 70\end{array}$ & $\begin{array}{l}\mathrm{F}>\mathrm{ou}=\mathrm{a} 45 \\
\text { mas }<\text { que } 50\end{array}$ & $\begin{array}{l}\mathrm{F}>\text { ou }=\text { a } 60 \\
\text { mas }<\text { que } 70\end{array}$ \\
\hline $\mathrm{D}<$ que 60 & $\mathrm{D}<$ que 45 & $\mathrm{D}<$ que 60 \\
\hline
\end{tabular}

Fonte: Elaborado pelos autores a partir da Capes (2013). 
O cálculo da métrica 1 alerta para uma deficiência do Programa. Para os três anos analisados, o programa seria avaliado como "FRACO", considerando o baixo percentual de docentes permanentes que ministraram 30h/aula. Em nenhum desses três anos o programa conseguiu atingir $70 \%$ do corpo docente. Portanto, devem ser adotadas estratégias a fim de garantir um corpo docente atuante.

O cálculo da métrica 2 se comporta de forma similar ao da métrica anterior. Para os três anos analisados, o programa seria avaliado como "REGULAR", pois, nos 3 anos apenas 50\% do corpo docentes apresentou liderança em projetos. Uma medida urgente é rever como está configurado o corpo docente e, ao mesmo tempo, fomentar a estruturação de projetos de pesquisa, em conformidade com as linhas de pesquisa do programa. Essa estruturação deve envolver o corpo docente e discente, com vistas ao fortalecimento da produção intelectual do programa, assim como sua inserção social e relacionamento com a comunidade acadêmica.

Ao se calcular a Métrica 3 é possível constatar que apenas 12 docentes concluíram duas orientações ou mais, do total de 19 docentes que integraram o corpo do Programa Alfa nesse triênio. Nesse aspecto, o programa seria avaliado como "FRACO".

\subsection{Corpo discente e Dissertações}

O Corpo discente e as dissertações defendidas pelo Programa foram analisados por três itens de avaliação. $\mathrm{O}$ primeiro item visa identificar a quantidade de dissertações aprovadas no período e sua distribuição em relação ao corpo discente titulado e ao corpo docente do programa. A análise deste item parte das métricas apresentadas na Figura 4.

Figura 4 - Dissertações aprovadas no período

\begin{tabular}{|c|c|}
\hline $\begin{array}{l}\text { Métrica } 1 \text { - Proporção de titulados no } \\
\text { ano-base considerando-se o número } \\
\text { de discentes no final do ano-anterior. } \\
\text { Conceito Proporção }(\%)\end{array}$ & $\begin{array}{l}\text { Métrica } 2 \text { - Proporção de docentes } \\
\text { permanentes com mais de } 8 \text { e menos } \\
\text { ou igual a } 12 \text { orientandos ao final de } \\
\text { cada ano. Caso um ou mais docentes } \\
\text { oriente } 13 \text { ou mais dissentes em cada } \\
\text { ano a classificação sofreu redução em } \\
\text { um grau. Conceito Proporção (\%) }\end{array}$ \\
\hline $\mathrm{MB}>\mathrm{ou}=\mathrm{a} 35$ & $\mathrm{MB}<\mathrm{ou}=\mathrm{a} 20$ \\
\hline $\mathrm{B}>\mathrm{ou}=\mathrm{a} 30$, mas $<$ que 35 & $\mathrm{~B}>$ que 20 e $<$ ou $=$ a 25 \\
\hline $\mathrm{R}>\mathrm{ou}=\mathrm{a} 25$, mas $<$ que 30 & $\mathrm{R}>$ que 25 e $<$ ou $=$ a 30 \\
\hline $\mathrm{F}>\mathrm{ou}=\mathrm{a} 20$, mas $<$ que 25 & $\mathrm{~F}>$ que 30 e $<$ ou $=$ a 35 \\
\hline $\mathrm{D}<$ que 20 & $\mathrm{D}>$ que 35 \\
\hline
\end{tabular}

Fonte: Elaborado pelos autores a partir da Capes (2013).

O Programa Alfa apresenta um resultado positivo para a Métrica 1. Nos anos 2013 e 2014 conseguiu atingir o conceito "MUITO BOM", pois conseguiu manter um percentual superior a 35\%. O resultado do cálculo da Métrica 2 é muito positivo para o programa, nos três anos ficando mantido um percentual inferior a $20 \%$.

O segundo item de avaliação buscou identificar a qualidade dos trabalhos de conclusão produzidos por discentes e egressos. Para tanto, orientou-se pelas métricas apresentadas na Figura 5 a seguir.

Figura 5 - Qualidade dos trabalhos de conclusão produzidos por discentes e egressos

\begin{tabular}{|c|c|}
\hline $\begin{array}{l}\text { Métrica } 1 \text { - Proporção das bancas de } \\
\text { trabalho de conclusão com } \\
\text { examinadores externos ao Programa. } \\
\text { Número de bancas de trabalho de } \\
\text { conclusão com examinadores } \\
\text { externos ao PPG dividido pelo total } \\
\text { de bancas examinadoras ou total de } \\
\text { titulados. } \\
\text { Conceito Proporção (\%) }\end{array}$ & $\begin{array}{l}\text { Métrica } 2 \text { - Proporção de trabalhos } \\
\text { de conclusão vinculados às linhas } \\
\text { de atuação. Deve-se, com base nos } \\
\text { resumos dos trabalhos de conclusão, } \\
\text { avaliar a vinculação dos mesmos às } \\
\text { linhas de atuação do programa. } \\
\text { Conceito Proporção (\%) }\end{array}$ \\
\hline $\mathrm{MB}>=95$ & $>=95$ \\
\hline $\mathrm{B}<$ que 95 e $>$ ou $=$ a 90 & $\mathrm{~B}<$ que 95 e $>$ ou $=$ a 90 \\
\hline $\mathrm{R}<$ que 90 e $>$ ou $=$ a 80 & $\mathrm{R}<$ que 90 e $>$ ou $=$ a 80 \\
\hline $\mathrm{F}<$ que $80 \mathrm{e}>$ ou $=\mathrm{a} 70$ & $\mathrm{~F}<$ que 80 e $>$ ou $=$ a 70 \\
\hline $\mathrm{D}<$ que 70 & $\mathrm{D}<$ que 70 \\
\hline
\end{tabular}

Fonte: Elaborado pelos autores a partir da Capes (2013). 
Ao ser calculada a Métrica 1, constatou-se um resultado positivo para o programa, pois, foram identificados membros externos em todas as bancas de defesa de dissertação realizadas entre os anos de 2013 e 2015 . Dessa forma, o Programa Alfa apresenta o conceito "Muito Bom". No entanto, a partir do cálculo da Métrica 2, já é possível identificar algumas inconsistências na vinculação das dissertações às linhas de pesquisa declaradas. Portanto, é preciso definir e fortalecer as linhas de pesquisas do programa e, ao mesmo tempo, validar as pesquisas em desenvolvido em cada linha de pesquisa.

O terceiro item de avaliação buscou analisar a aplicabilidade dos trabalhos produzidos. A partir da leitura dos resumos das dissertações produzidas, buscou-se identificar a aplicabilidade do trabalho de mestrado desenvolvido junto a setores não acadêmicos, órgãos públicos e privados, incluindo o terceiro setor.

\subsection{Proposta de Gestão}

A partir da análise das informações da proposta, corpo docente, corpo discente e dissertações do Programa Alfa, observou-se que o programa não se encontra em um cenário favorável. Diante desta constatação, é necessário estimular ações a fim de atenuar as fragilidades do programa e fortalecer os aspetos positivos.

As comparações entre a avaliação anterior e a situação atual do programa, sem as alterações propostas, podem ser visualizadas no Quadro 2.

Quadro 2 - Comparação das avaliações do Programa Alfa

\begin{tabular}{|c|c|c|c|}
\hline QUESITO & PESO & $\begin{array}{c}\text { AVALIAÇÃO } \\
\text { ANTERIOR }\end{array}$ & $\begin{array}{c}\text { SITUAÇÃO } \\
\text { ATUAL }\end{array}$ \\
\hline PROPOSTA & 0 & Regular & Regular \\
\hline CORPO DOCENTE & 20 & Regular & Bom \\
\hline $\begin{array}{c}\text { CORPO DISCENTE E } \\
\text { TRABALHOS DE } \\
\text { CONCLUSÃO }\end{array}$ & 30 & Não Aplicável & Muito Bom \\
\hline
\end{tabular}

Fonte: Elaborado pelos autores (2016).

Assim, recomenda-se um planejamento das atividades que possam interferir de alguma forma na avaliação do programa. A fim de garantir a representatividade dos envolvidos nas atividades do programa, sugere-se a adoção de oficinas, construídas a partir de Grupos de Trabalhos compostos de forma mista, contemplando: docentes, discentes e membros externos. Por envolver um grande número de atores, a proposta é de que os grupos definam entre seus pares representantes capazes de levar suas demandas previamente discutidas.

Cada Linha de Pesquisa pode ser um Grupo de Trabalho. Na nova configuração proposta por este estudo seriam os três: Grupo de Trabalho 1 - Sistemas de Avaliação e Gestão Acadêmica; Grupo de Trabalho 2 - Análises, Modelos e Técnicas em Gestão Universitária; e Grupo de Trabalho 3 - Políticas Públicas e Sociedade.

Os Grupos de Trabalho seriam responsáveis por discutir, elaborar propostas e planejar metas contemplando os itens de avaliação do programa. Dessa forma, o resultado do Grupo de Trabalho seria envolver todos os atores do Programa Alfa na sua avaliação, promover uma reflexão sobre suas responsabilidades individuais.

O produto ideal, para cada linha de pesquisa, seria o mapeamento de possíveis locais para publicação de material científico, tais como revistas e eventos, nas respectivas áreas das linhas, estabelecendo um cronograma. Além disso, o estabelecimento de metas de produção científica, como artigos e relatórios técnicos. Para findar o primeiro ciclo, outra etapa importante é a validação dos dados inseridos na Plataforma Sucupira. Os atores devem periodicamente verificar se toda a produção foi declarada e inserida na plataforma e, se as informações estão corretas. Neste processo, envolver o colegiado e validar os dados a serem submetidos à avaliação da CAPES.

Este processo é um ciclo, ou seja, após o encerramento da última etapa deve-se retornar à primeira. As etapas são ilustradas pela Figura 6. 
Figura 6 - Gestão dos quesitos do programa

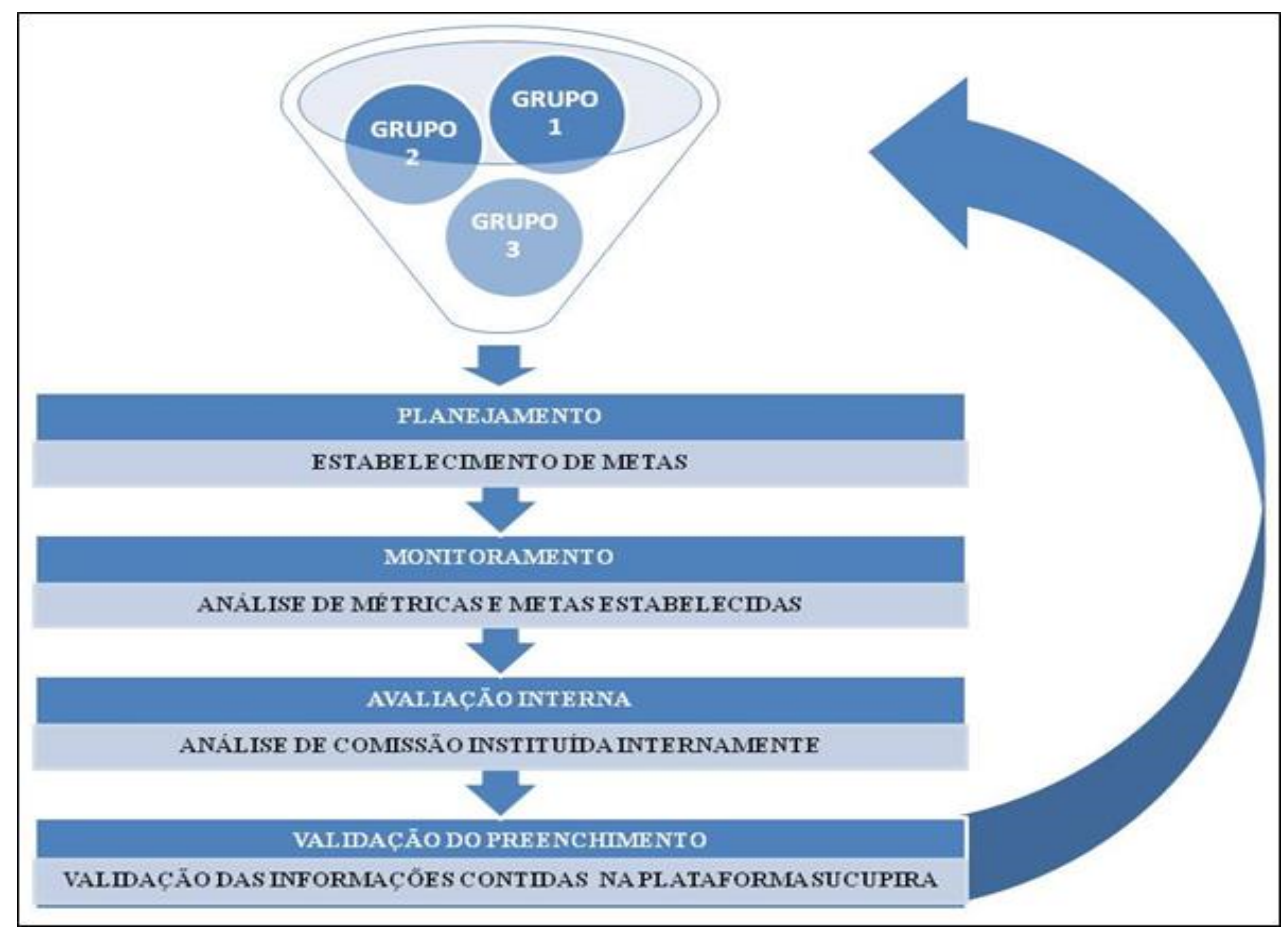

Fonte: Elaborado pelos autores (2016).

Além de estar atento à gestão dos quesitos, o programa deve atenção ao resultado da avaliação realizada pela CAPES e, principalmente, ao prazo para o pedido de reconsideração. Este período é crucial para que seja justificado algum item mal avaliado e que não foi esclarecido corretamente pelo programa.

Quanto à atuação individual dos envolvidos no programa, é possível elencar algumas ações com vistas à elevação da nota do programa para o atual período avaliativo (2013-2016), são elas: cada docente produzir e registrar no Currículo Lattes ao menos 50 pontos; concluir a orientação de ao menos duas dissertações, ter ao menos 5 produções técnicas; os discentes se comprometerem com o prazo para a defesa de dissertação, além de colaborar com a produção dos docentes. A secretaria deve apoiar o corpo docente e discente, no monitoramento das atividades e no registro destas informações.

\section{CONSIDERAÇÕES FINAIS}

Este trabalho esteve centrado em propor mudanças à Gestão do Programa Alfa a partir do Sistema de Avaliação da CAPES - Sistema de Avaliação ao qual o programa está submetido.

A partir do trabalho da Comissão Instituída, por uma portaria de 2015 do programa, foram observadas algumas deficiências como a ênfase em questões teóricas, não diferenciando o programa do formato acadêmico; e má distribuição do corpo docente nos projetos e nas linhas de pesquisa.

Observou-se que o programa conta com um corpo docente com perfil acadêmico e profissional adequado. Além disso, o Programa Alfa não apresenta problemas quanto ao número de docentes que fazem parte de outro programa de pós-graduação. A variação do corpo docente é pequena e não representa problemas na avaliação do programa.

Verificou-se que no período compreendido entre os anos 2013 e 2015, o Programa Alfa apresentou uma boa proporção de titulados considerando o número de discentes no final do ano anterior, dessa forma, manteve-se com um conceito "Muito Bom".

Por fim, chega-se a uma proposta de melhorias à Gestão do Programa Alfa. Neste sentido, recomendou-se um planejamento das atividades do Programa Alfa que interfiram na sua avaliação, objetivando alinhamento e consonância com os critérios de avaliação da CAPES. 


\section{REFERÊNCIAS}

ABREU JUNIOR, N. Sistema(s) de avaliação da educação superior brasileira. Cad. CEDES, Campinas, v. 29, n. 78, p. 257269, Aug. 2009. Disponível em: <http://www.scielo.br/scielo.php?script=sci_arttext\&pid=S0101-

32622009000200008\&lng=en\&nrm=iso >. Acesso em: 10 abr. 2015.

ASSIS, R. M.; BONIFÁCIO, N. A. A formação docente na universidade: ensino, pesquisa e extensão. Revista Educação e Fronteiras On-line, Dourados, v. 1, n. 3, p.36-50, 2011. Quadrimestral. Disponível em:

<http://www.periodicos.ufgd.edu.br/index.php/educacao/article/viewFile/1515/pdf_97>. Acesso em: 10 abr. 2015.

BERTOLDI, W. J.; COLOSSI, N.; RONCHI, C. C. Desenvolvimento Integrado em IES. In: MELO, P. A.; COLOSSI, N. Cenários da gestão universitária na contemporaneidade. Florianópolis: Insular, 2004. p. 171-184.

BRASIL. Decreto n 29.741, de 11 de julho de 1951. [1951]. Institui uma Comissão para promover a Campanha Nacional de Aperfeiçoamento de pessoal de nível superior. Disponível em:

<http://www2.camara.leg.br/legin/fed/decret/1950-1959/decreto-29741-11-julho-1951-336144-publicacaooriginal-1pe.html >. Acesso em: 01 abr. 2015.

BRASIL. Lei 10.861, de 14 de abril de 2004. [2004]. Institui o Sistema Nacional de Avaliação da Educação Superior SINAES e dá outras providências. Disponível em: <http://www.planalto.gov.br/ccivil_03/_ato2004-

2006/2004/lei/l10.861.htm >. Acesso em: 31 set. 2015.

BRASIL. Portaria Normativa n 17, de 28 de dezembro de 2009. [2009]. Dispõe sobre o mestrado profissional no âmbito da Fundação Coordenação de Aperfeiçoamento de Pessoal de Nível Superior - CAPES. Diário Oficial da União no 248. Seção 1, p. 20. Disponível em: <http://www.capes.gov.br/images/stories/download/avaliacao/avaliacao-n/PortariaMEC-17-2009.pdf>. Acesso em: 31 set. 2015.

CAPES. Coordenação de Aperfeiçoamento de Pessoal de Nível Superior. Ministério da Educação. Competências. 2012. Disponível em: <http://www.capes.gov.br/acesso-ainformacao/5418-competencias>. Acesso em: 20 mar. 2015.

CAPES. Ministério da Educação. Relatório de avaliação 2010-2012 trienal 2013. Brasília, 2013. Disponível em: <http://docs.google.com/viewer?a=v\&pid=sites\&srcid=Y2FwZXMuZ292LmJyfHRyaWVuYWwtMjAxM3xneDo2YzNkMjU 2ZTdmY2M0ODAx>. Acesso em: 01 jun. 2015.

CAPES. Coordenação de Aperfeiçoamento de Pessoal de Nível Superior. Ministério da Educação. Sobre a Avaliação. 2014. Disponível em: <http://www.capes.gov.br/avaliacao/sobre-a-avaliacao>. Acesso em: 20 mar. 2015.

CAPES. Ministério da Educação. Módulo coleta de dados. 2015. Disponível em:

<http://www.capes.gov.br/avaliacao/plataforma-sucupira/modulo-coleta-de-dados>. Acesso em: 20 jun. 2015.

CHAUÍ, M. A universidade pública sob nova perspectiva. Revista brasileira de educação - Anped, Poços de Caldas, p.515, 05 out. 2003. Quadrimestral. Disponível em:

<http://www.anped.org.br/rbe/rbedigital/RBDE24/RBDE24_04_MARILENA_CHAUI.pdf>. Acesso em: 01 abr. 2015.

CONSELHO NACIONAL DE DESENVOLVIMENTO CIENTÍFICO E TECNOLÓGICO (CNPq). Sobre a plataforma Lattes. 2015. Disponível em: <http://lattes.cnpq.br/>. Acesso em: 20 jun. 2015.

GIL, A. C. Métodos e técnicas de pesquisa social. 5. ed. São Paulo: Atlas, 1999.

GIL, A. C. Como elaborar projetos de pesquisa. 4. ed. São Paulo: Atlas, 2002.

INSTITUTO NACIONAL DE ESTUDOS E PESQUISAS EDUCACIONAIS ANÍSIO TEIXEIRA (INEP). SINAES. 2015. Disponível em: <http://portal.inep.gov.br/superior-sinaes>. Acesso em: 15 jun. 2015.

MACCARI, E. A. et al. Proposta de um modelo de gestão de programas de pós-graduação na área de Administração a partir dos sistemas de avaliação do Brasil (CAPES) e dos Estados Unidos (AACSB). Revista de Administração, São Paulo, v. 49, n. 2, p. 369-383, jun. 2014. Trimestral. Disponível em: <http://www.scielo.br/pdf/rausp/v49n2/12.pdf >. Acesso em: 20 mar. 2015.

NEPOMUCENO, L. D. O.; COSTA, H. G. Mapeamento de percepções na avaliação dos impactos do mestrado profissional no perfil do seu egresso. Produção, São Paulo, v. 22, n. 4, p. 865-873, dez. 2012. Disponível em 
$<$ http://www.scielo.br/scielo.php?script=sci_arttext\&pid=S0103-65132012000400018\&lng=en\&nrm=iso >. Acesso em: 15 ago. 2015.

OLIVEIRA, J. F.; FONSECA, M.; AMARAL, N. C. Avaliação, desenvolvimento institucional e qualidade do trabalho acadêmico. Educ. rev., Curitiba, n. 28, p. 71-87, dez. 2006. Disponível em: <http://www.scielo.br/scielo.php?script=sci_arttext\&pid=S0104-40602006000200006\&lng=en\&nrm=iso >. Acesso em: 10 abr. 2015.

SAMPAIO, R. M; LANIADO, R. N. Uma experiência de mudança da gestão universitária: o percurso ambivalente entre proposições e realizações. Revista de Administração Pública, Rio de Janeiro, v. 43, n. 1, p. 151-174, 2009. Bimestral. Disponível em: <http://bibliotecadigital.fgv.br/ojs/index.php/rap/article/view/6683/5266>. Acesso em: 05 abr. 2013.

SANTOS, E. G.; SADALA, M. G. S.; BORGES, S. X. A. Avaliação institucional: por que os atores silenciam? Educ. Real., Porto Alegre, v. 37, n. 2, p. 551-568, ago. 2012. Disponível em:

<http://www.scielo.br/scielo.php?script=sci_arttext\&pid=S2175-62362012000200012\&lng=en\&nrm=iso >. Acesso em: 20 maio 2015.

SCHLICKMANN, R. Administração universitária: Desvendando o campo científico no Brasil. 2013. 287 f. Tese (Doutorado) - Curso de Programa de Pós-graduação em Administração, Departamento de Ciências da Administração, Universidade Federal de Santa Catarina, Florianópolis, 2013.

SILVA, E.L.; MENEZES, E. M. Metodologia da pesquisa e elaboração de dissertação. 4. ed. Florianópolis: UFSC, 2005. $138 \mathrm{p}$.

SILVA FILHO, R. L. L. Gestão universitária e seus desafios. São Paulo 1998. Disponível em: <http://www.institutolobo.org.br/imagens/pdf/artigos/art_008.pdf>. Acesso em: 05 abr. 2013.

SOUZA, A. C.; FIALHO, F. A. P.; OTANI, N. TCC: métodos e técnicas. Florianópolis: Visual Books, 2007. 160 p.

YIN, R. K. Estudo de Caso: Planejamento e Métodos. 5. ed. Porto Alegre: Bookman, 2015. 290 p.

ZANETTI, M. A.; BERTOLINI, M. A.; SILVA, M. R. A avaliação institucional no projeto da nova LDB. Educ. rev., Curitiba, n. 11, p. 121-124, dez. 1995. Disponível em: <http://www.scielo.br/scielo.php?script=sci_arttext\&pid=S0104 40601995000100015\&lng=en\&nrm=iso >. Acesso em: 10 abr. 2015. 